\title{
Kavak odununun bazı fiziksel özellikleri üzerine vakum atmosferinde uygulanan ısıl işlemin etkisi
}

\author{
Bekir Cihad Bal ${ }^{1 *(D)}$, Murat Kilavuz ${ }^{2}$ (D)
}

\section{$\ddot{O} \mathbf{z}$}

Odunun istenmeyen özelliklerinin iyileştirilmesi için farklı bazı modifikasyon yöntemleri uygulanmaktadır. Son y1llarda bu modifikasyon yöntemlerinden olan 1sıl işlem uygulaması diğerlerine göre daha fazla uygulanmaya başlanmıştır. Endüstriyel uygulamalarda farklı bazı 1sıl işlem metotları kullanılmaktadır. Bu metotlarda, 1sı taşı1ıı araç, işlem süresi ve işlem sıcaklığı gibi faktörler farklılık göstermektedir. Bu çalışmada, vakum ortamında, taşınım yöntemiyle 1sı iletimi yapılarak uygulanan 1sıl işlem metodunda, farklı vakum seviyelerinde 1 sıl işlemin kavak odunun bazı fiziksel özellikleri üzerine etkisi araştırılmıştır. Testler vakumlu etüvde ve $210^{\circ} \mathrm{C}$ sicaklıkta ve 3 saat süre ile $0,200,400,600$ mbar vakum altında uygulanmıştır. Test örneklerinin tam kuru yoğunluk, denge rutubeti miktarı, teğet genişleme, radyal genişleme, boyuna genişleme ile hacmen genişleme yüzdeleri gibi fiziksel özellikleri belirlenmiştir. Elde edilen veriler kontrol grubuna göre karşılaştırmalı olarak incelenmiştir. Gruplar arasında istatistiksel olarak fark olup olmadığ belirlenmiştir. Birbirlerinden farklılık gösteren gruplar Duncan testi ile belirlenmiştir. Elde edilen verilere göre; grupların genişleme yüzdeleri arasında istatistiksel olarak önemli seviyede farklılık tespit edilmiştir.

Anahtar kelimeler: Kavak odunu, 1sıl işlem, vakum atmosferi, fiziksel özellikler

\section{The effect of heat treatment in vacuum atmosphere on some physical properties of poplar wood}

\begin{abstract}
Some different modification methods are applied to improve the unwanted properties of wood. In recent years, heat treatment application, which is one of these modification methods, has been applied more than others. Some different heat treatment methods are used in industrial applications. In these methods, factors such as heat transfer media, processing time and process temperature differ. In this study, the effect of heat treatment at different vacuum levels on some physical properties of poplar wood was investigated in the heat treatment method applied by convection method in vacuum environment. The tests were carried out in a vacuum oven at $210^{\circ} \mathrm{C}$ and under $0,200,400,600$ mbar vacuum for 3 hours. Physical properties of the test specimens such as oven dry density, equilibrium moisture content, tangential swelling, radial swelling, longitudinal swelling and volumetric swelling percentage were determined. The obtained data were analysed comparatively with respect to the control group. Whether there was a statistical difference between the groups was determined by the ANOVA test. Groups differing from each other were determined by Duncan test. According to the data obtained; a statistically significant difference was found between the swelling percentages of the groups.
\end{abstract}

Keywords: Poplar wood, heat treatment, vacuum atmosphere, physical properties 


\section{Giriş}

Son yıllarda 1sıl işlem ile ilgili olarak yapılan çalışmaların artması yeni metotların gelişmesine yol açmış ve bu sayede Avrupa pazarında 1sıl işlem uygulanmış ahşap kullanımı artmıştır. Günümüzde uygulanan birçok farklı ısıl işlem metodu bulunmaktadır. Bu metotlar Korkut ve Kocaefe (2009) tarafından şu şekilde not edilmiştir; Thermowood (Finlandiya), PlatoWood-Lignius-Lambowood (Hollanda), Retification process (Retiwood)-New Option wood- Le Bois Perdure (Fransa), Hot Oil treatment (OHT) (Almanya), Calignum (İsvec), Thermabolite (Rusya), Huber Holz (Avusturya), Wood treatment technology (WTT) (Danimarka), Westwood (Amerika, Kanada, Rusya). Bu metotların hepsi çok yaygın kullanım bulamamıştır. Günümüzde en fazla kullanılan ısıl işlem metotları Platowood (Hollanda), Thermowood (Finlandiya), Retification ve Le-Bois Perdure (Fransa) ve Oil-heat treatment wood (Almanya) şeklinde olduğu Korkut ve ark. (2008) tarafından bildirilmiştir.

Türkiye'de odunun ısıl işlem yöntemi ile modifiye edilmesi birkaç işletme tarafindan uygulanmaktadır. Yöntemin endüstriyel olarak Türkiye'de yaygınlaşmaya başlaması diğer bazı ülkelere göre daha geç olmuştur. Türkiye'de ilk olarak Novawood firması 1sıl işlem görmüş ahşap malzeme üretimine başlamıştır. Bolu ilinde faaliyet göstermektedir. Bu firma Thermowood yöntemi kullanarak ahşaba 1 sıl işlem uygulamaktadır. Yıllık ortalama $18000 \mathrm{~m}^{3}$ 1sıl işlem görmüş ahşap kapasitesine sahiptir. Birçok ülkeye ihracat yapmaktadır (URL1, 2019). Bu firmanın yanında, Antalya ilinde faaliyet gösteren NASwood firması da yine Thermowood ${ }^{\circledR}$ yöntemi kullanarak 1sıl işlem görmüş ahşap malzeme üreten bir firmadır (URL2, 2019). Sakarya'da faaliyet gösteren TANtimber firması y1llık $11000 \mathrm{~m}^{3}$ kapasite ile çalışmaktadır (URL3 2019).

Önceki çalışmalarda, 1sıl işlem uygulanan farklı odun örnekleri üzerinde bazı önemli testler yapılmıştır. Yapılan bu testlerle, odun örneklerinin fiziksel özelliklerinde, mekanik özeliklerinde (Jamsa ve Viitaniemi 2001; Emperier ve ark., 2003; Mburu ve ark., 2008; Esteves ve Pereira 2009; Aydemir ve ark., 2011; Bal 2014), kimyasal içeriğinde (Brito ve ark. 2008; Candelier ve ark. 2013a), yüzey renginde, parlaklığında (Ayata ve ark. 2018a; Ayata 2020) ve pürüzlülüğünde (Korkut ve Güller 2008; Ayata ve ark. 2018b) ne gibi değişikliklerin meydana geldiği araştırılmıştır. Özellikle bazı çalışmalarda, ısı taşıma aracının (azot gazı, su buharı, kızgın yağ vs.) 1sıl işlemin etkisini nasıl değiştirdiği belirlenmeye çalışılmıştır (Michell 1988; Candelier ve ark. 2013a; Candelier 2013b; Candelier ve ark. 2014; Bal 2015).

Isının taşınımı ile ilgili olarak üç farklı yöntem bulunmaktadır. Bunlar; iletim (kondüksiyon), taşınım (konveksiyon) ve 1şınım (radyasyon) yöntemleridir. İletim yönteminde direk temas eden katı malzemeler vasıtasıyla 1sı iletimi yapılmaktadır. Taşınım yönteminde ise hava veya sıvı madde ile 1sı taşınmaktadır. Vakum ortamında yapılan 1sıl işlem metodunda, ortamdaki hava miktarı uygulanan vakumla azaltılmaktadır. Isıl işlem gören keresteler, yüzeylerine temas eden metal plakalar vasitasıyla temas yöntemi ile isitılmaktadır. Böylece, daha hızlı ve etkin bir 1sı iletimi yapılmaktadır. Ayrıca, vakum ortamında hava miktarı azaltıldığı için, odun bileşenlerinin havadaki oksijenle reaksiyona girip bozulmaları azalmaktadir (K1lavuz 2020).

$\mathrm{Bu}$ çalışmanın amacı, vakum ortamında ve taşınım yöntemiyle ısı iletimi yapılarak uygulanan 1sıl işlem uygulamasında, vakum miktarının etkisi ile, odunun bazı fiziksel özelliklerinde meydana gelen değişmeleri araştırmaktır. Bu amaç için, tam kuru yoğunluk, denge rutubeti miktarı, teğet genişleme, radyal genişleme, boyuna genişleme ile hacmen genişleme yüzdeleri gibi fiziksel özellikleri araştırılmıştır. 


\section{Materyal ve Metot}

\subsection{Materyal}

$\mathrm{Bu}$ çalışmada, testler için kavak (Populus subsp.) odunu kullanılmıştır. Kavak odunu Kahramanmaraş ilinde, özel bir kavak yetiştiricisinden tomruk olarak satın alma yoluyla temin edilmiştir. Tomruklar bir kereste atölyesinde biçilmiş ve keresteler elde edilmiştir. Biçme işlemi TS 2470 'e göre yapılmıştır. Tomruklar kaba biçme sonrası, tahtalara biçilmiş ve bu haliyle doğal kurutmaya bırakılmıştır. İki aylık süreden sonra bu tahtalardan 2 x 2 ×150 cm ölçüsünde çıtalar elde edilmiştir. Bu çıtalardan fiziksel testler için test örnekleri hazırlanmıştır. Aynı çıtalardan yan yana kesilen test örnekleri ile test grupları oluşturularak homojen test grupları elde edilemeye çalışılmıştır.

\subsection{Metot}

Fiziksel özelliklerin tespiti için, dört farklı deney grubu ve birde kontrol grubu olacak gruplar hazırlanmıştır. Test örnekleri hava kurusu rutubet haline gelmesi için $20 \pm 3^{\circ} \mathrm{C}$ ve $\% 65 \pm 5$ bağıl nem şartlarında bekletilmiştir. Daha sonra 1 sıl işlem uygulanmıştır. Kontrol grubuna hiçbir işlem uygulanmamıştır. Vakum uygulanmayan gruba (0 mbar grubu) 1 sıll işlem uygulanmış ancak vakumlu etüv içerisine vakum uygulanmamıştır. Bu grup ile 1sıl işlemin etkisi belirlenmeye çalışılmıştır. 200, 400 ve 600 mbar deney grubu için etüv içerisine vakum uygulanmış ve bu şartlarda 1sıl işlem uygulanmıştır. $\mathrm{Bu}$ gruplarda vakumun ve 1 sıl işlemin etkisi belirlenmeye çalışılııştır. Isıl işlem $210^{\circ} \mathrm{C}$ sıcaklık altında 3 saat boyunca Şekil 1'de görülen vakumlu etüvde devam etmiştir. Bu süreye 1sıtma periyodu dahildir. Test örnekleri bu sürenin sonunda etüvden çıkarılmış ve naylon poşetlere bırakılarak hava ile teması önlenmiştir.

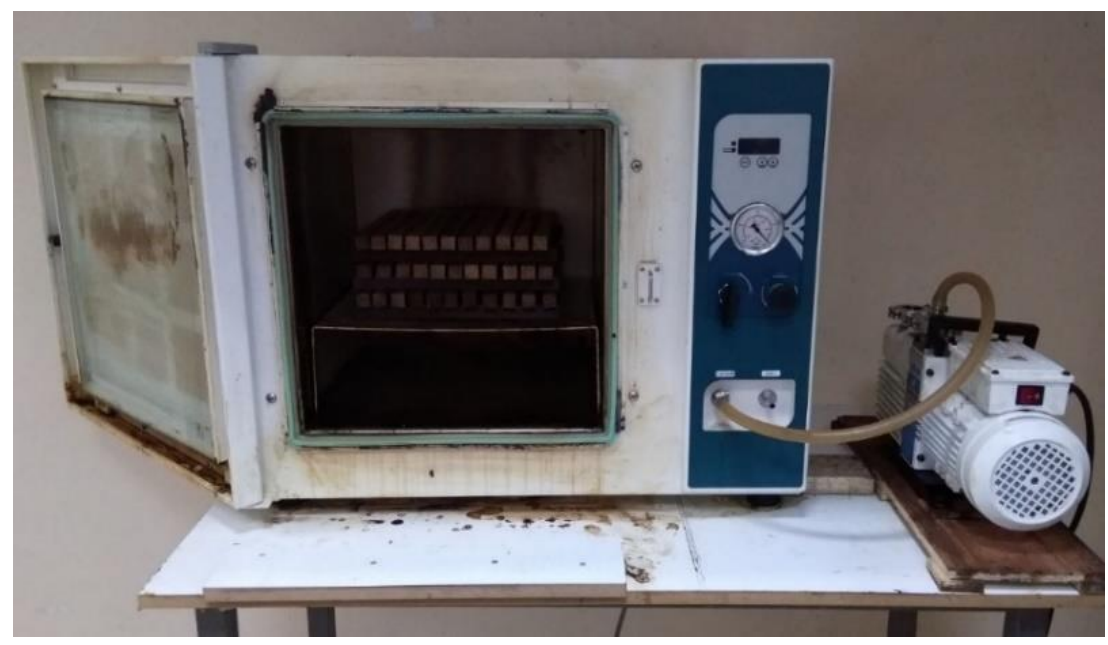

Şekil 1. Test örneklerine vakumlu etüvde 1 sıl işlem uygulamas1

Tam kuru yoğunluk ölçümleri TS 2472 de belirtilen kriterlere göre yapılmıştır. Rutubet miktarının belirlenmesi için TS 2471numaralı standarttan yararlanılmıştır. Genişleme miktarının belirlenmesi için TS 4084 ve TS 4086 numaralı standartlar kullanılmıştır. Bu standartlara göre deney parçaları; tabanı 20x20 mm ve lif doğrultusundaki uzunluğu $30 \mathrm{~mm}$ olan prizma biçiminde hazırlanmıştır. Deney parçaları kurutma dolabında $103 \pm 2^{\circ} \mathrm{C}$ 'de sıcaklıkta değişmez boyutlara ulaşıncaya kadar kurutulmuştur. Bu durumdaki ölçüleri ve ağırlı̆̆ alınmıştır. Daha sonra, deney parçaları ağırlığı değişmez hale gelinceye kadar bir kap içerisinde $20 \pm 5{ }^{\circ} \mathrm{C}$ sicaklıkta damıtık su içerisine 2 hafta süre ile batırılmıştır. Sonra tam yaş haldeki son ölçüleri alınmış ve genişleme yüzdeleri hesaplanmıştır.

Laboratuvar denemeleri sonrası, fiziksel özelliklere ait testlerden elde edilen bulgular Excel programına kaydedilmiş ve düzenlenmiştir. Bazı istatistik değerler (aritmetik ortalama, standart sapma, maksimum değer ve minimum değer) bu program vasıtasıyla elde edilmiştir. Gruplar arasında önemli 
bir fark olup olmadığı basit varyans analizi ile (One-Way ANOVA) SPSS programında belirlenmiştir. Duncan testi ile farklılık gösteren gruplar belirlenmiştir.

\section{Bulgular ve Tartışma}

Laboratuvar şartlarında yapılan ısıl işlem uygulaması sonrası test örnekleri uygun şekilde kondisyonlanmış ve sonra bazı fiziksel özellikler belirlenmiştir. Bu özellikler; tam kuru yoğunluk (TKY), denge rutubeti miktarı (DRM), teğet genişleme (TG), radyal genişleme (RG), boyuna genişleme (BG), hacimsel genişleme ( $\mathrm{HG}$ ) yüzdeleridir. Elde edilen fiziksel özelliklere ait istatistiksel değerlerden (ID), aritmetik ortalama ( $\bar{x}$ ), standart sapma (ss), maksimum değer (mak) ve minimum değer (min) Çizelge 1'de verilmiştir. Çizelge incelendiğinde bu fiziksel özelliklerin farklı miktarlarda değiştiği görülmektedir. Kontrol grubuna göre en büyük değişme ise, hiç vakum uygulanmayan (0 mbar) deney grubunda gerçekleştiği görülmektedir. Vakum uygulanan gruplarda en az değişme ise 600 mbar deney grubunda meydan gelmiştir.

Çizelge 1. Fiziksel özelliklere ait istatistiksel değerler (Kılavuz 2019)

\begin{tabular}{|c|c|c|c|c|c|c|c|}
\hline \multirow{2}{*}{ Gruplar } & \multirow{2}{*}{ İD } & TKY & DRM & TG & RG & BG & HG \\
\hline & & $\mathrm{kg} / \mathrm{m}^{3}$ & $\%$ & $\%$ & $\%$ & $\%$ & $\%$ \\
\hline \multirow{4}{*}{$\begin{array}{c}\text { Kontrol } \\
\text { grubu }\end{array}$} & $\overline{\mathrm{x}}$ & 385 & 11.5 & 8.24 & 3.94 & 0.47 & 12.64 \\
\hline & ss & 20 & 0.4 & 1.18 & 0.90 & 0.16 & 0.73 \\
\hline & mak & 447 & 12.2 & 9.88 & 6.08 & 0.77 & 13.85 \\
\hline & $\min$ & 345 & 10.9 & 5.44 & 2.80 & 0.13 & 11.08 \\
\hline \multirow{4}{*}{$\begin{array}{c}0 \\
\mathrm{mBar}\end{array}$} & $\overline{\mathrm{x}}$ & 363 & 5.7 & 4.83 & 2.50 & 0.29 & 7.63 \\
\hline & ss & 19 & 0.7 & 1.26 & 1.26 & 0.13 & 0.90 \\
\hline & mak & 408 & 7.3 & 6.37 & 7.98 & 0.49 & 8.86 \\
\hline & $\min$ & 323 & 4.7 & 0.25 & 1.22 & 0.10 & 5.83 \\
\hline \multirow{4}{*}{$\begin{array}{c}200 \\
\text { mBar }\end{array}$} & $\overline{\mathrm{x}}$ & 368 & 5.8 & 5.40 & 2.75 & 0.26 & 8.41 \\
\hline & ss & 30 & 1.2 & 0.82 & 0.86 & 0.10 & 1.11 \\
\hline & mak & 452 & 7.0 & 6.91 & 4.81 & 0.52 & 10.30 \\
\hline & $\min$ & 331 & 4.4 & 3.48 & 1.58 & 0.10 & 6.06 \\
\hline \multirow{4}{*}{$\begin{array}{c}400 \\
\mathrm{mBar}\end{array}$} & $\overline{\mathrm{x}}$ & 370 & 6.0 & 5.54 & 2.75 & 0.25 & 8.54 \\
\hline & Ss & 15 & 0.7 & 0.85 & 1.33 & 0.11 & 1.75 \\
\hline & mak & 406 & 7.5 & 7.50 & 6.12 & 0.48 & 12.02 \\
\hline & $\min$ & 342 & 4.8 & 3.61 & 1.18 & 0.10 & 6.37 \\
\hline \multirow{4}{*}{$\begin{array}{l}600 \\
\mathrm{mBar}\end{array}$} & $\bar{x}$ & 372 & 6.3 & 5.55 & 2.94 & 0.27 & 8.76 \\
\hline & ss & 21 & 0.5 & 0.79 & 0.83 & 0.13 & 0.88 \\
\hline & mak & 423 & 7.2 & 6.97 & 4.54 & 0.64 & 10.80 \\
\hline & $\min$ & 339 & 5.6 & 3.99 & 1.97 & 0.10 & 6.63 \\
\hline
\end{tabular}

Yapılan laboratuvar denemeleri sonunda elde edilen tam kuru yoğunluk değerleri Çizelge 1'de verilmiştir. En yüksek yoğunluk değeri $385 \mathrm{~kg} / \mathrm{m}^{3}$ ile kontrol grubunda ve en küçük yoğunluk değeri ise $363 \mathrm{~kg} / \mathrm{m}^{3}$ olarak 0 mbar grubunda vakum uygulanmayan şartlarda yapılan denemeler sonunda elde edilmiştir. Vakum uygulanan gruplardan 600 mbar grubu isıl işlemden en az etkilenen grup olarak tespit edilmiştir. Bu değerlere ait ANOVA testi sonuçları ise aşağıda Çizelge 2'de gösterilmiştir. Çizelge incelendiğinde ANOVA testi sonucuna göre gruplar arasında tam kuru yoğunluk değerleri birbirlerinden istatistiksel olarak önemli derecede $(\mathrm{P}<0.01)$ farkl11ık olduğu tespit edilmiştir. 
Bal ve Kılavuz, Mobilya ve Ahşap Malzeme Araştırmaları Dergisi, 4 (1), 30-39

Çizelge 2. Isıl işlemin yoğunluk üzerine etkisine ilişkin ANOVA testi sonuçları

\begin{tabular}{|c|c|c|c|c|c|c|}
\hline $\begin{array}{c}\text { Fiziksel } \\
\text { özellik }\end{array}$ & $\begin{array}{l}\text { Varyans } \\
\text { kaynağı }\end{array}$ & $\begin{array}{l}\text { Kareler } \\
\text { toplamı }\end{array}$ & $\begin{array}{c}\text { Serbestlik } \\
\text { derecesi }\end{array}$ & $\begin{array}{l}\text { Kareler } \\
\text { ortalaması }\end{array}$ & F oranı & $\begin{array}{c}\text { Önem } \\
\text { seviyesi }\end{array}$ \\
\hline $\begin{array}{l}\text { Tam kuru } \\
\text { yoğunluk }\end{array}$ & $\begin{array}{c}\text { Gruplar arasi } \\
\text { Gruplar içi } \\
\text { Toplam }\end{array}$ & $\begin{array}{c}7966.8 \\
68060.2 \\
76027.0\end{array}$ & $\begin{array}{c}4 \\
145 \\
149\end{array}$ & $\begin{array}{c}1991.69 \\
469.38\end{array}$ & 4.24 & $0.003^{*}$ \\
\hline \multicolumn{7}{|c|}{ *ileri düzeyde önemli } \\
\hline
\end{tabular}

Çizelge 2'de ANOVA testi sonuçları verilmiştir. Ancak ANOVA testi sonuçlarında göre hangi grupların birbirlerinden farklılık gösterdiği tespit edilememektedir. Gruplar arasındaki farklılıkları görebilmek için Duncan çoklu ayrım testi yapılmıştır. Duncan testi sonuçları Çizelge 3'de verilmiştir. Bu çizelge incelendiğinde, en küçük yoğunluk değeri 0 mbar grubunda ve en büyük yoğunluk değeri ise kontrol grubunda tespit edilmiştir. 400 ile 600 mbar grupları arasında istatistiksel olarak bir farklılık tespit edilmemiştir. Buradan elde edilen verilere göre 1sıl işlem esnasında vakum uygulanmasının odun bileşenlerindeki bozulmayı azalttığı söylenebilir.

Çizelge 3. Tam kuru yoğunluk (TKY) gruplarına ait Duncan testi sonuçları

\begin{tabular}{|c|c|c|}
\hline Gruplar & $\begin{array}{c}\text { Örnek sayıs } \\
(\mathbf{n})\end{array}$ & $\begin{array}{c}\text { TKY } \\
\left(\mathbf{k g} / \mathbf{m}^{\mathbf{3}}\right)\end{array}$ \\
\hline $0 \mathrm{mBar}$ & 30 & $362 \mathrm{~A}^{*}$ \\
\hline $200 \mathrm{mBar}$ & 30 & $368 \mathrm{~A}$ \\
\hline $400 \mathrm{mBar}$ & 30 & $370 \mathrm{AB}$ \\
\hline $600 \mathrm{mBar}$ & 30 & $370 \mathrm{AB}$ \\
\hline Kontrol & 30 & $385 \mathrm{~B}$ \\
\hline
\end{tabular}

*Birbirlerinde farklılık gösteren gruplar büyük harflerle gösterilmiştir.

A en küçük değeri göstermektedir.

Denge rutubeti miktarına (DRM) ait istatistik veriler Çizelge 1'de verilmiştir. Bu test verilerine ait ANOVA testi sonuçları ise Çizelge 4'de gösterilmiştir. $\mathrm{Bu}$ çizelge incelendiğinde, yapılan 1 sıl işlem denemelerinin, denge rutubeti miktarı üzerine çok ileri düzeyde etkili olduğu görülmektedir.

Çizelge 4. Isıl işlemin denge rutubetine etkisine ilişkin ANOVA testi sonuçları

\begin{tabular}{|ccccccc|}
\hline $\begin{array}{c}\text { Fiziksel } \\
\text { özellik }\end{array}$ & $\begin{array}{c}\text { Varyans } \\
\text { Kaynağı }\end{array}$ & $\begin{array}{c}\text { Kareler } \\
\text { toplamı }\end{array}$ & $\begin{array}{c}\text { Serbestlik } \\
\text { derecesi }\end{array}$ & $\begin{array}{c}\text { Ortalama } \\
\text { kare }\end{array}$ & F oranı & $\begin{array}{c}\text { Önem } \\
\text { seviyesi }\end{array}$ \\
\hline \multirow{2}{*}{$\begin{array}{c}\text { Denge } \\
\text { Rutubeti }\end{array}$} & $\begin{array}{c}\text { Gruplar } \\
\text { arası }\end{array}$ & 750.9 & 4 & 187.7 & 498.4 & $0.000^{*}$ \\
Miktarı & $\begin{array}{c}\text { Gruplar içi } \\
\text { Toplam }\end{array}$ & $\begin{array}{c}54.6 \\
805.5\end{array}$ & 145 & 0.4 & & \\
\hline & $*$ İstatistiksel olarak çok ileri düzeyde önemli $(\mathrm{P}<0.001)$ & \\
\hline
\end{tabular}

Yapılan 1sıl işlem denemeleri sonunda elde edilen denge rutubeti miktarları arasında istatistiksel olarak önemli derecede farklılıklar olduğunu yapılan ANOVA testi sonucundan anlıyoruz. Ancak, hangi grupların birbirlerinden farklılık gösterdiğini ise Çizelge 5'de verilen 
Duncan testi sonuçlarında görebiliriz. Bu çizelge incelendiğinde, 0, 200 ve 400 mbar vakum uygulanan gruplar arasında denge rutubetinin farklılık göstermediği ancak, kontrol grubu ve 600 mbar vakum uygulanan grupların diğerlerinde daha farklı denge rutubeti miktarına sahip oldukları görülmektedir. Özellikle kontrol grubu ile kıyaslandığında ısıl işlem uygulanmış olan grupların denge rutubeti miktarının yaklaşık yarı yarıya azaldığı görülmektedir. Isıl işlem uygulamasının ahşap malzemeye uygulanarak elde edilmeye çalışılan en önemli çıktılarda birisi ahşabın rutubet alışverişini azaltmaktır.

Çizelge 5. Denge rutubeti gruplarının karşılaştırılmasına ait Duncan testi sonuçları

\begin{tabular}{|c|c|c|}
\hline Gruplar & Örnek sayısı (n) & DRM (\%) \\
\hline $0 \mathrm{mBar}$ & 30 & $5,7 \mathrm{~A}$ \\
\hline $200 \mathrm{mBar}$ & 30 & $5,9 \mathrm{~A}$ \\
\hline $400 \mathrm{mBar}$ & 30 & $5,9 \mathrm{~A}$ \\
\hline $600 \mathrm{mBar}$ & 30 & $6,3 \mathrm{~B}$ \\
\hline Kontrol & 30 & $11,5 \mathrm{C}$ \\
\hline
\end{tabular}

Teğet yönde, radyal yönde, boyuna yönde ve hacmen genişleme yüzdelerine ait ANOVA testi sonuçları ise Çizelge 6'da aşağıda verilmiştir. Bu çizelge incelendiğinde, genişleme yüzdelerinin 1sıl işlem uygulamasından çok ileri düzeyde önemli derecede ( $\mathrm{P}$ $<0.001$ ) etkilendiği tespit edilmiştir. Çizelgede verilen F değeri göz önüne alındığında ise, en fazla etkilenen değişkenin hacmen genişleme yüzdesi olduğu görülmektedir.

Çizelge 6. Genişleme üzerine 1sıl işlemin etkisini gösteren ANOVA testi

\begin{tabular}{|c|c|c|c|c|c|c|}
\hline $\begin{array}{c}\text { Fiziksel } \\
\text { özellik }\end{array}$ & $\begin{array}{l}\text { Varyans } \\
\text { kaynağı }\end{array}$ & $\begin{array}{l}\text { Kareler } \\
\text { toplamı }\end{array}$ & $\begin{array}{c}\text { Serbestlik } \\
\text { derecesi }\end{array}$ & $\begin{array}{c}\text { Kareler } \\
\text { ortalaması }\end{array}$ & F oranı & $\begin{array}{c}\text { Önem } \\
\text { seviyesi }\end{array}$ \\
\hline \multirow{3}{*}{$\begin{array}{c}\text { Teğet } \\
\text { genişleme }\end{array}$} & Gruplar aras1 & 213.8 & 4 & \multirow{3}{*}{$\begin{array}{c}53.46 \\
0.99\end{array}$} & \multirow[t]{3}{*}{54.08} & \multirow[t]{3}{*}{$0.000^{*}$} \\
\hline & Gruplar içi & 143.3 & 145 & & & \\
\hline & Toplam & 357.1 & 149 & & & \\
\hline \multirow{3}{*}{$\begin{array}{c}\text { Radyal } \\
\text { genişleme }\end{array}$} & Gruplar aras 1 & 37.6 & 4 & \multirow{3}{*}{$\begin{array}{l}9.41 \\
1.11\end{array}$} & \multirow[t]{3}{*}{8.48} & \multirow[t]{3}{*}{0.000} \\
\hline & Gruplar içi & 160.9 & 145 & & & \\
\hline & Toplam & 198.5 & 149 & & & \\
\hline \multirow{3}{*}{$\begin{array}{l}\text { Boyuna } \\
\text { genişleme }\end{array}$} & Gruplar aras 1 & 0.8 & 4 & \multirow{3}{*}{$\begin{array}{l}0.20 \\
0.02\end{array}$} & \multirow[t]{3}{*}{10.95} & \multirow[t]{3}{*}{0.000} \\
\hline & Gruplar içi & 2.7 & 145 & & & \\
\hline & Toplam & 3.5 & 149 & & & \\
\hline \multirow{3}{*}{$\begin{array}{l}\text { Hacmen } \\
\text { genişleme }\end{array}$} & Gruplar aras 1 & 466.8 & 4 & \multirow{3}{*}{$\begin{array}{c}116.69 \\
1.25\end{array}$} & \multirow[t]{3}{*}{92.99} & \multirow[t]{3}{*}{0.000} \\
\hline & Gruplar içi & 182.0 & 145 & & & \\
\hline & Toplam & 648.7 & 149 & & & \\
\hline
\end{tabular}

Yapılan ANOVA testi sunucunda kavak odununun 1sıl işlem uygulamasında çok ileri düzeyde önemli derecede etkilendiği ve gruplar arasında farklılıklar olduğu belirlenmiştir. Birbirlerinden farklılık gösteren grupları belirlemek için Duncan çoklu ayrım testi yapılmıştır. Yapılan bu test sonucunda elde edilen veriler Çizelge 7'de verilmiştir. Bu çizelge incelendiğinde, teğet genişleme ve hacmen genişleme değerlerinin, kontrol grubu ile 600 mBar vakum uygulanan grubun diğer gruplardan farklılık gösterdiği belirlenmiştir. Radyal ve 
boyuna genişleme yüzdelerinde kontrol grubundan farklılık vardır, ancak, deney grupları arasında farklılık belirlenememiştir.

Çizelge 7. Genişleme miktarları gruplarına ait Duncan testi sonuçları

\begin{tabular}{|c|c|c|c|c|c|}
\hline Gruplar & $\begin{array}{c}\text { Örnek sayısı } \\
(\mathbf{n})\end{array}$ & $\begin{array}{c}\text { TG* } \\
(\boldsymbol{\%})\end{array}$ & $\begin{array}{c}\text { RG } \\
(\boldsymbol{\%})\end{array}$ & $\begin{array}{c}\text { BG } \\
(\boldsymbol{\%})\end{array}$ & $\begin{array}{c}\text { HG } \\
(\boldsymbol{\%})\end{array}$ \\
\hline $0 \mathrm{mBar}$ & 30 & $4.8 \mathrm{~A}$ & $2.5 \mathrm{~A}$ & $0.27 \mathrm{~A}$ & $7.6 \mathrm{~A}$ \\
\hline $200 \mathrm{mBar}$ & 30 & $5.4 \mathrm{AB}$ & $2.7 \mathrm{~A}$ & $0.27 \mathrm{~A}$ & $8.4 \mathrm{AB}$ \\
\hline $400 \mathrm{mBar}$ & 30 & $5.5 \mathrm{AB}$ & $2.7 \mathrm{~A}$ & $0.28 \mathrm{~A}$ & $8.5 \mathrm{~B}$ \\
\hline $600 \mathrm{mBar}$ & 30 & $5.6 \mathrm{~B}$ & $2.9 \mathrm{~A}$ & $0.30 \mathrm{~A}$ & $8.7 \mathrm{~B}$ \\
\hline Kontrol & 30 & $8.2 \mathrm{C}$ & $3.9 \mathrm{~B}$ & $0.46 \mathrm{~B}$ & $12.6 \mathrm{C}$ \\
\hline
\end{tabular}

*TG: teğet genişleme, RG: Radyal genişleme, BG: Boyuna genişleme, HG: Hacmen genişleme

$\mathrm{Bu}$ çalışmada, 5 grup test örneği oluşturulmuş ve bu test örneklerinin bazı fiziksel özellikleri belirlenmiştir. Vakum altında 1sıl işlem uygulanan gruplardan yoğunluğu, denge rutubeti ve genişleme yüzdeleri en fazla azalan grup 200 mbar vakum uygulanan grup olmuştur. Elde edilen bulgulara göre; 1sıl işlem uygulamasının kavak odununun burada denenen fiziksel özelliklerini azalttığı belirlenmiştir. Bu konuda yapılan önceki çalışmalarda, diğer bazı araştırmacılar tarafından da benzer sonuçlar rapor edilmiştir. (Bekta ve Niemz 2003; Korkut ve ark., 2008; Esteves ve Pereira 2009; Gündüz ve ark., 2009; Korkut ve Kocaefe 2009; Bal ve Bektaş 2012; Bal 2013a, b; Aydemir ve Gündüz 2009; Orhan 2017; Bal 2018). Yapılan bu çalışmalarda, özellikle, fiziksel özelliklerden denge rutubetinin azalmasının ve genişleme miktarının azalmasının ahşap malzemenin kullanım yerinde uzun yıllar sorunsuz kullanılabilmesi açısından önemli olduğu vurgulanmıştır. Denge rutubetinin düşmesi, odunun içinde bulunduğu ortamdan daha az rutubet almasını sağlamaktadır. Böylece, daralma ve genişleme gibi odun-su ilişkilerine bağlı olarak gelişen fiziksel olaylar azalmaktadır. Odun ne kadar az hücre çeperine su bağlanırsa o kadar az genişler. Böylece, kullanım yerinde servis süresince meydana gelen rutubet alışverişleri sonunda ahşap malzemenin genişleme ve daralması sonunda oluşan deformasyonun önüne geçilmiş olur.

$\mathrm{Bu}$ çalışma sonunda elde edilen ikinci önemli sonuç vakum miktarının fiziksel özellikler üzerine olan etkisidir. Isıl işlem esnasında uygulanan vakum ahşabın daha az zarar görmesine neden olmuştur. Odunun genişleme miktarındaki azalma vakum miktarı artıkça azalmıştır. Bunun en önemli nedeni, ısıl işlem esnasında, odun bileşenleri başta hemiselülozlar olmak üzere bozulmaya başlar. Sicaklık arttıkça selüloz ve ligninde zarar görür (Mburu ve ark., 2008; Esteves and Pereira 2009: Korkut ve Kocaefe 2009). Extraktif madde miktarı ve lignin miktarı artar (Brito ve ark.2008), yüksek sıcaklıkta ısıl işlem uygulaması hidroksil gruplarını azaltır (Aydemir ve ark., 2011). Ancak, 1sıl işlem uygulanan odun oksijen ile teması azaltılır veya tamamen engellenirse bu durumda, hücre bileșenlerinin oksijenle reaksiyona girmesi önlenebilir ve sonuçta odun daha az zarar görür. Bu nedenle, bazı ısıl işlem metotlarında azot gazı veya sıcak bitkisel yăg veya doymuş buhar kullanılmaktadır. Yapılan bu çalışmada, vakum miktarının etkisi belirlenmeye çalışılmıştır. Bazı önceki çalışmalarda, farklı ortamlarda ısıl işlemin odun özellikleri üzerine etkisi araştırılmıştır. Michell (1998), Candelier ve ark., (2013a) ve Emperier (2003) azot gazı varlığında ve vakum altında yapılan ısıl işlemin odunun kimyasal bileşenleri ve biyolojik dayanıklılığı üzerine etkisi araştırılmıştır. Candelier ve ark., (2013b) ve Candelier ve ark. (2014) ve Bal (2018) tarafından yapılan çalışmada ise azot gazı altında ve vakum atmosferinde yapılan isıl işlemin odunun mekanik özellikleri üzerine etkisi araştırılmıştır. Bir başka çalışmada ise normal atmosfer ortamında ve sıcak bitkisel yağ içerisinde yapılan isıl işlemin odunun fiziksel özellikleri üzerine etkisi incelenmiştir ( $\mathrm{Bal}$ 2015). Bu çalışmalarda elde edilen verilere göre 1sıl işlem uygulaması esnasında kullanılan 1sı taşıyıcıya göre (hava, yağ, azot gazı, su buharı, vakum) 1sıl işlemin 
odun özellikleri üzerine etkisi farklı olmaktadır. Endüstriyel olarak vakum altında yapılan 1sıl işlem uygulaması esnasında, ısı ahşap malzemeye metal plakalar vasıtasıyla iletilmektedir. Isı iletim (kondüksiyon) yöntemi ile yapılmaktadır. İletim yönteminde direk temas eden katı malzemeler vasıtasıyla ısı iletimi yapılmaktadır. Taşınım yönteminde ise hava veya sıvı madde ile 1sı taşınmaktadır. Vakum ortamında yapılan 1sıl işlem metodunda, ortamdaki hava miktarı uygulanan vakumla azaltılmaktadır. Isıl işlem gören ahşap malzeme, yüzeylerine temas eden metal plakalar vasitasıyla temas yöntemi ile 1sitılmaktadır. Böylece, daha hızlı ve etkin bir 1sı iletimi yapılmaktadır. Ayrıca, vakum ortamında hava miktarı azaltıldığı için, odun bileşenlerinin havadaki oksijenle reaksiyona girip bozulmaları azaltılmaktadır. Elde edilen verilere göre; vakum miktarı arttıkça fiziksel özelliklerde vakum uygulanmayan gruba göre artış kaydedilmiştir. Bu durum fiziksek özellikler bakımından istenmeyen bir durumdur.

\section{Sonuçlar ve Öneriler}

$\mathrm{Bu}$ çalışmada, vakum ortamında ve taşınım yöntemiyle 1sı iletimi yapılarak uygulanan 1sıl işlem uygulamasında, vakum miktarının etkisi ile, odunun bazı fiziksel özelliklerinde meydana gelen değişmeler araştırılmıştır. Bu amaç için, tam kuru yoğunluk, denge rutubeti miktarı, teğet genişleme, radyal genişleme, boyuna genişleme ile hacmen genişleme yüzdeleri gibi fiziksel özellikleri araştırılmıştır. Elde edilen verilere göre;

- Yapılan bu çalışmada, vakum altında yapılan ısıl işlem uygulaması esnasında vakum miktarının değişmesi ile odunun fiziksel özelliklerinde meydana gelen değişmeler tespit edilmiştir.

- Yoğunluk miktarı, denge rutubeti miktarı ve teğet, radyal ve boyuna yönde genişleme miktarları azalmıştır. Bu azalmalar en fazla vakum uygulanmayan (0 mBar) grupta elde edilmiştir.

- Bu çalışmada ölçülen fiziksel özelliklerden, vakum uygulanan gruplarda en fazla azalma 200 mBar grubunda bulunan test örneklerinde meydana gelmiştir.

- Bundan sonra yapılacak çalışmalarda, vakum altında uygulanan 1sıl işlemin odunun kimyasal özellikleri üzerine etkisinin araştırılması önerilir.

\section{Teşekkür}

$\mathrm{Bu}$ makale, Murat Kılavuz isimli yazarın "Vakum atmosferinde yapılan 1sıl işlemin kavak odununun teknolojik özellikleri üzerine etkisinin araştırılması" başlıklı yüksek lisans tezinden üretilmiştir. Çalışma herhangi bir fon tarafından desteklenmemiştir.

\section{Kaynaklar}

Ayata, Ü, Gürleyen, T, Gürleyen, L., (2018a), Effect of heat treatment on color and glossiness properties of zebrano, sapelli and merbau woods, Mobilya ve Ahşap Malzeme Araştırmaları Dergisi, 1 (1), 11-20, DOI: 10.33725/mamad.428913

Ayata, Ü, Gürleyen, T., Gürleyen, L., Çakıcıer, N., (2018b), Determination of surface roughness parameters of heat-treated and untreated scotch pine, oak and beech woods. Mobilya ve Ahşap Malzeme Araştırmaları Dergisi, 1 (1), 46-50, DOI: 10.33725/mamad. 433945

Ayata, Ü., (2020), Ayous odununun bazı teknolojik özelliklerinin belirlenmesi ve 1sıl işlemden sonra renk ve parlaklık özellikleri, Mobilya ve Ahşap Malzeme Araştırmaları Dergisi, 3 (1), 22-33, DOI: 10.33725/mamad.724596

Aydemir, D., Gündüz, G., (2009), Ahşabın Fiziksel, Kimyasal, Mekaniksel ve Biyolojik Özellikleri Üzerine Isıyla Muamelenin Etkisi. Bartın Orman Fakültesi Dergisi, 15; 7181. 
Aydemir, D., Gündüz, G., Altuntas, E., Ertas, M., Sahin, H. T., Alma, M. H., (2011), Investigating changes in the chemical constituents and dimensional stability of heattreated hornbeam and Uludağ fir wood, BioResources, 6(2), 1308-1321.

Bal, B.C., Bektaş, İ., (2012), The effects of heat treatment on the physical properties of juvenile wood and mature wood of Eucalyptus grandis. Bioresources, 7(4), 5117-5127.

Bal, B.C. (2013a), Effects of Heat Treatment on the Physical Properties of Heartwood and Sapwood of Cedrus Libani, Bioresources, 8(1), 211-219.

Bal, B.C. (2013b), A Comparative Study of the Physical Properties of Thermally Treated Poplar Wood and Plane Wood, Bioresources, 8(4), 6493-6500.

Bal, B.C., (2014), Some physical and mechanical properties of thermally modified juvenile and mature black pine wood, European Journal of Wood and Wood Products, 72, 6166, DOI: 10.1007/s00107-013-0753-9

Bal, B.C. (2015), Physical properties of beech wood thermally modified in hot oil and in hot air at various temperatures, Maderas: Ciencia y Tecnologia, 17(4), 789-798.

Bal, BC, (2018), A Comparative Study of Some of the Mechanical Properties of Pine Wood Treated in Vacuum, Nitrogen, and Air Atmospheres, Bioresources, 13(3), 5504-5511.

Bekhta, P., P. Niemz (2003), Effect of high temperature on the change in colour, dimensional stability and mechanical properties of spruce wood, Holzforschung 57:539-546.

Brito, J.O., Silva, F.G., L Eao, M.M. Almeida, G., (2008), Chemical Composition changes in Eucalyptus and Pinus Woods submitted to Heat Treatment, Bioresource Technology, 99 (2008) 8545-8548. 10.1016/j.biortech.2008.03.069

Candelier, K., Dumarçay, S., Pétrissans, A., Desharnais, L., Gérardin, P., Pétrissans, M. (2013a), Comparison of chemical composition and decay durability of heat-treated wood cured under different inert atmospheres: Nitrogen or vacuum. Polymer degradation and Stability, 98(2), 677-681. DOI:10.1016/j.polymdegradstab.2012.10.022

Candelier, K., Dumarçay, S., Pétrissans, A., Gérardin, P., Pétrissans, M. (2013b), Comparison of mechanical properties of heat-treated beech wood cured under nitrogen or vacuum. Polymer degradation and stability, 98(9), 1762-1765.DOI: 10.1016/j.polymdegradstab. 2013.05.026

Candelier, K., Dumarçay, S., Pétrissans, A., Gérardin, P., Pétrissans, M. (2014), Advantage of vacuum versus nitrogen to achieve inert atmosphere during, Pro Ligno, 10(4), 10-17.

Epmeier, H., M. Westin, A.O. Rapp and T. Nilsson (2003), Comparison of Properties of Wood Modified by 8 Different Methods - Durability, Mechanical and Physical Properties. The First European Conference on Wood Modification Ghent, Belgium. 9080656526

Esteves, BM., Pereira, HM. (2009), Wood modification by heat treatment: A review, BioResources 4(1), 370-404

Gunduz G, Aydemir D, Kaygin B, Aytekin A., (2009), The Effect of Treatment Time on Dimensionally Stability, Moisture Content and Mechanical Properties of Heat-Treated Anatolian Chestnut (Castanea sativa Mill.) Wood. Wood Research 54 (2), 117-126.

Jamsa S, Viitaniemi P (2001), Heat treatment of wood - Better durability without chemicals, Review on heat treatments of wood, In proceedings of Special Seminar held in Antibes, France. 
Kılavuz M., (2019), Vakum atmosferinde yapılan 1sıl işlemin kavak odununun teknolojik özellikleri üzerine etkisinin araştırılması, KSÜ, Fen Bilimleri Enstitüsü, Yüksek Lisans Tezi, Kahramanmaraş.

Korkut DS., Güller B., (2008), The effects of heat treatment on physical properties and surface roughness of red-bud maple (Acer trautvetteri Medw.) wood, Bioresource technology, 99 (2008) 2846-2851.

Korkut, S., Korkut, D.S., Bekar İ., (2008), Okaliptüs (Eucalyptus camaldulensis Dehn.) Odununun Bazı Teknolojik Özellikleri Üzerine Isıl İşlemin Etkisi, I. Okaliptüs sempozyumu, 15-17 Nisan 2008, Tarsus-Türkiye.

Korkut, S., Kocaefe, D., (2009), Isıl İşlemin Odun Özellikleri Üzerine Etkisi. Düzce Üniversitesi Ormanc1l1k dergisi, 5(2), 11-34.

Mburu, F., Dumarçay, S., Bocquet, J.F., Petrissans, M. and Gerardin, P., (2008), Effect of Chemical Modifications Caused by Heat Treatment on Mechanical Properties of Grevillea robusta Wood, Polymer Degradation and Stability 93 (2008) 401-405.

Michell, P. H., (1988), Irreversible property changes of small loblolly pine specimens heated in air, nitrogen, or oxygen, Wood and Fiber Science,20(3), 320-335.

Orhan H., (2017), Kavak Odununun Bazı Fiziksel ve Mekanik Özellikleri Üzerine Azot Gazı Varlığında Yapılan Isıl İşlemin Etkilerinin Belirlenmesi, KSÜ, Fen Bilimleri Enstitüsü, Yüksek Lisans Tezi, Kahramanmaraş.

TS 2470 Odunda Fiziksel ve Mekaniksel Deneyler İçin Numune Alma Metotları ve Genel Özellikler, Türk Standartları Enstitüsü, Ankara.

TS 2471 Odunda Fiziksel ve Mekaniksel Deneyler İçin Rutubet Miktarı Tayini, Türk Standartları Enstitüsü, Ankara.

TS 2472 Odunda Fiziksel ve Mekaniksel Deneyler İçin Hacim Yoğunluk Değerinin Tayini, Türk Standartları Enstitüsü, Ankara.

TS 4084, Odunda Radyal ve Teğet Doğrultuda Şişmenin Tayini, TSE, Ankara.

TS 4086 Odunda Hacimsel Şişmenin Tayini, Türk Standartları Enstitüsü, Ankara.

URL1, (2019), http://www.novawood.com/, son erişim tarihi; 29.06.2019.

URL2, (2019), http://www.nashouse.com.tr, son erişim tarihi; 29.06.2019.

URL3, (2019), https://www.tantimber.com/tr, son erişim tarihi; 29.06.2019. 